\title{
The Temperature in Xinjiang-Tibet Roadbed Variation Analysis
}

\author{
Liyun Wang ${ }^{1, a^{*}}$, Xuesong Mao ${ }^{1, b}$, Shuguang Luo ${ }^{2, c}$ \\ ${ }^{1}$ Highway school, Changan University, Xi'an, Shanxi, China \\ ${ }^{2}$ Hunan vocational college of software, Xiang'tan,Hunan,China \\ a 1457546241@qq.com, ${ }^{b}$ xuesongxian@aliyun.com, c 459524834@qq.com
}

\begin{abstract}
Keywords:Xinjiang-Tibet highway; Subgrade; Temperature field; Dynamic change
Abstract: The temperature change in roadbed is a process of dynamic change, is the key factor that influence the performance of subgrade. In order to research the subgrade temperature changes in permafrost regions, based on national highway 219 line Xinjiang-Tibet highway monitoring project, observed the temperature inside the subgrade engineering. By the project, we can monitor the internal temperature change process in the position of natural and roadbed and analyzes the internal temperature of the subgrade of space-time change rule. According to the temperature change process, we analyze what the semi-rigid base asphalt concrete pavement construction influence the phase change temperature. This article through the temperature field test of typical cross section in permafrost regions, researches what temperature change influence the properties of subgrade embankment.
\end{abstract}

\section{Introduction}

The original fragile heat balance condition of permafrost was changed after construction of subgrade in permafrost region ${ }^{[1]}$. Due to strong endothermic and block evaporation asphalt pavement after paving asphalt pavement in permafrost regions, which changed the original water heat balance state under the subgrade, thus begetting temperature change under subgrade and the rapid heating and melting permafrost ${ }^{[2]}$. So it is very necessary to make research for temperature change condition in the permafrost roadbed for preventing roadbed diseases.

Temperature is an important factor for highway roadbed diseases ${ }^{[3]}$. Yuzhi Zhang, study on subgrade geothermal features with the change of time and depth distribution and predict the change trend in geothermal field ${ }^{[4]}$; Long Jin, obtained the change law of subgrade deformation changing with the roadbed height under the condition of different temperatures ${ }^{[5]}$; Ying Jin, stress field is influenced by the outside world to distribution after the roadbed constructed; Mingyi Zhang numerical simulation to the various subgrade forms and analyzed the change laws of temperature field $^{[6]}$.

Temperature change in subgrade is a process of dynamic change. There is no temperature monitoring data for the Xinjiang-Tibet highway in subgrade in current at home. So the long-term tracking observation for internal temperature of the subgrade is the basis of analyzing the subgrade internal temperature change rule and it provide specific data for the rule of variation of embankment temperature field numerical simulation. 


\section{Engineering situation}

\section{Test section situation}

Xinjiang-Tibet highway (G219 line) is located in the roof of the world. The north of this road is yecheng county of xinjiang uygur autonomous region and south ends into transcribing county, Tibet autonomous region. This road present south-north direction in general, full-length $2143 \mathrm{~km}$. Xinjiang-Tibet highway was built in 1950, because of its special construction period, bad natural environment, as well as the limitations of national resources, it is still a gravel road with low level of technique, disaster relief ability weak, poor road conditions and cannot ensuring safety in general. This way cannot meet the demand of border emergency special transport.

The Xinjiang-Tibet highway rebuilding engineering use the semi-rigid base asphalt concrete pavement in the whole line, aiming at improving the traffic capacity of road significantly.

\section{Natural environment characteristics}

The average elevation of national highway 219 line Xinjiang-Tibet highway is above 4500 meters (qinghai-tibet highway at an altitude of about $4000 \mathrm{~m}$ ), extremely temperature is 40 ${ }^{\circ} \mathrm{C}$, which is the world's highest highway. Almost all sections along the road are no man's land with alpine hypoxia. Bad weather, complicated geological and geographical conditions along the high altitude thin air and air oxygen content is low.

This project is located in north cold arid plateau climate. Its climate characteristic mainly is the annual temperature and daily temperature difference. Big evaporation, dry air and longtime sunshine is often.

\section{Experimental design}

\section{Temperature sensors buried on the site}

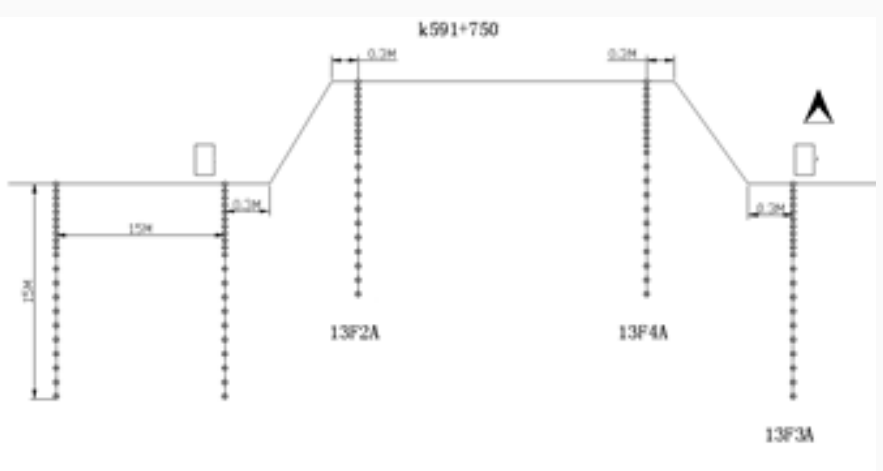

Figure 1 temperature sensor setting

From the angle of the underground water level and maximum frozen depth chose typical sections, embedding temperature sensor to test of subgrade. It is concluded that the distribution of the internal temperature in the roadbed. Sensor layout scheme is shown in figure 1, K591 + 750 section set four ground temperature observation holes, respectively include natural orifice (named as $13 \mathrm{~F} 1 \mathrm{~F}$ ), left slope (named as $13 \mathrm{~F} 1 \mathrm{~A}$ ), the left shoulder (named as 13F2A), on the right shoulder (named as 13F4A), right toe (named as 13F3A). Each hole depth is 15 meters, every hole layout 21 temperature sensor.

Temperature measuring device with high precision thermistors, temperature measurement precision is $0.01{ }^{\circ} \mathrm{C}$. In $-50{ }^{\circ} \mathrm{C}$ to $50{ }^{\circ} \mathrm{C}$ temperature range for calibration. Test instrument use FULK digital multimeter, temperature measurement precision is $0.01{ }^{\circ} \mathrm{C}$. 


\section{Cycle test in embankment temperature field}

In order to study on the temperature change rule of subgrade, the collection of temperature time selected in higher temperature in August, September and October. What is worth mention is the temperature sensor not only buried in the slope foot and shoulder, also buried in the natural orifice, which can analyze how the pavement construction of semi-rigid base asphalt concrete influence on embankment temperature field.

\section{Test and analysis to the embankment temperature field}

The temperature in the roadbed vary as seasonal cycles. This article based on the ground temperature observation data, analyze the changing rule in the internal temperature field. Due to the left and right sides of the embedding position sensor is symmetrical and internal temperature of the roadbed in accord with depth change rule, just analyze the left side of the subgrade.

\section{Internal temperature of the subgrade vertical distribution}

From slope foot and shoulder temperature time-varying figure (figure 2), atmospheric temperature influence on the depth of the ground temperature at around $4 \mathrm{~m}$. In addition, within the scope of about $1 \mathrm{~m}$ depth, internal temperature increases with the increase of depth in the ground slope foot and shoulder, which explain embankment temperature changes lags the change of temperature.
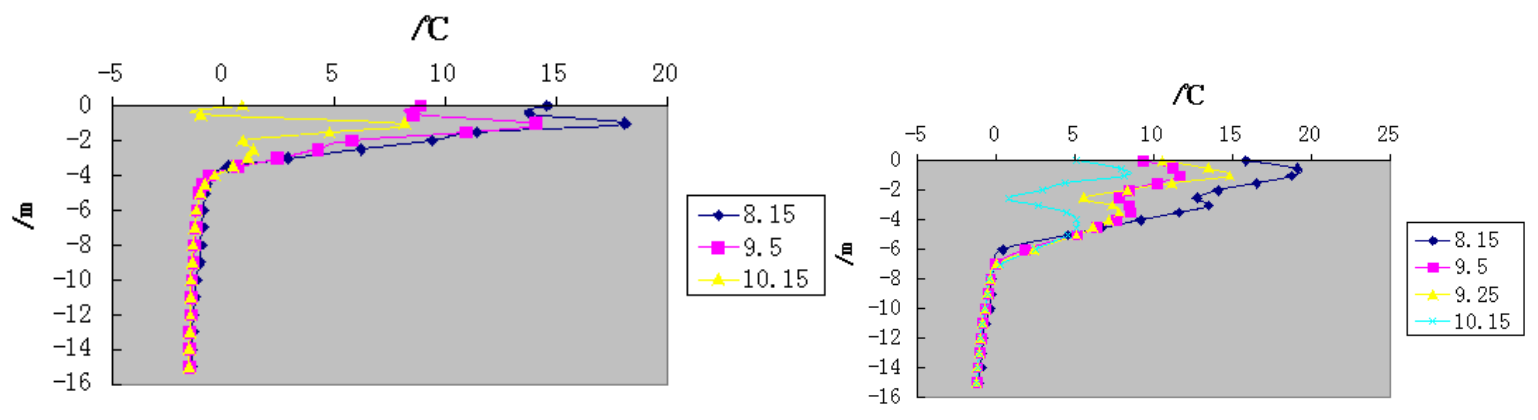

Figure 2 temperature vary with depth in 2014 years at different time under the slope foot and shoulder curves

Ground temperature at $0{ }^{\circ} \mathrm{C}$ above in all in August, subgrade soil is in the melt state and ground temperature from the roadbed depth $1 \mathrm{~m}$ decreased with the increase of depth; In September, the temperature is around $10{ }^{\circ} \mathrm{C}$, decreasing ground temperature along the depth direction, temperature changes biggest within 2-4 m depth; In October, outside air temperature is close to $0{ }^{\circ} \mathrm{C}$, temperature and ground temperature is still positive, and more uniformly distributed along the depth direction, the temperature is about $4{ }^{\circ} \mathrm{C}$.

\section{The influence of asphalt concrete pavement on embankment temperature field}

For the further analyze how the semi-rigid base asphalt concrete pavement construction of roadbed influence on the temperature field, compared the change of temperature with depth below in the natural position, slope foot and shoulder (as shown in figure 2 and figure 3 ). In the same depth of roadbed, ground temperature change rule of repeating the same every year. Along with the increase of the thickness of pavement subgrade, the internal temperature change lags behind atmospheric temperature change.

Because asphalt concrete pavement absorbs heat, the pavement laying for subgrade was greatly influenced by the temperature change, especially in the range from 0 to $2 \mathrm{~m}$ depth. Below $4 \mathrm{~m}$ depth, 
temperature change in the natural position is similar to slope foot and shoulder temperature changes, temperature is close to $0{ }^{\circ} \mathrm{C}$. The construction of semi-rigid base asphalt concrete pavement broken the balance of internal temperature and made the permafrost table upward displacement. As a result of the action of temperature potential in embankment internal will cause a lot of moisture migration, internal water continues to increase, which in turn will lead to the destruction of the pavement structure.

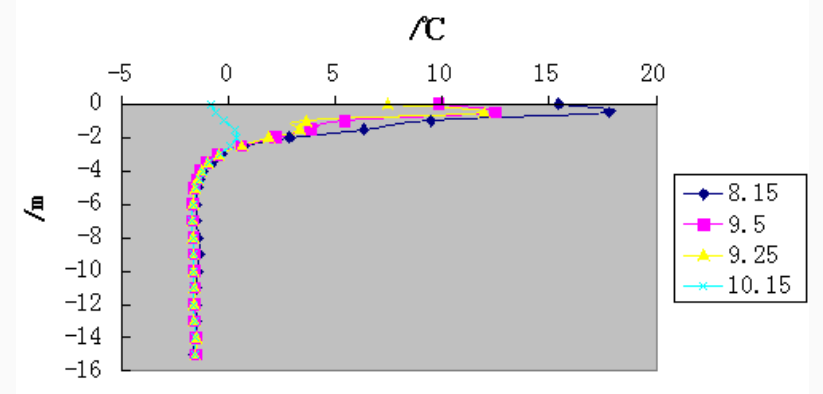

Figure 3 temperature vary with depth in 2014 years at different time in natural location curve

\section{conclusion}

(1) According to national highway 219 line Xinjiang-Tibet highway monitoring project, observe the temperature inside the subgrade and analyze the temperature space-time change rule in the internal subgrade.

(2) Based on the temperature test data, from the angle of the hydrothermal change characteristics analyze how the asphalt concrete pavement influence on embankment temperature field.

\section{References:}

[1] Yindong $\mathrm{Xu}$. Flaky ventilation roadbed construction control in permafrost area [J]. Journal of qinghai traffic science and technology, 2013, 1:008.

[2] Ge Liu, jian-bing Chen. Plateau permafrost regions wide subgrade water heat transfer law research [J]. Chinese and foreign road 2014, 4:34 (2)

[3] Shaoping Jiang. Permafrost region analysis and treatment technology of roadbed disease [J]. Modern highway 2013, 8, 16.

[4] Yuzhi Zhang, yan-liang du. Seasonal frozen soil area of high speed railway subgrade geothermal distribution study [J]. Journal of rock mechanics and engineering, 2014, 6, 33 (6)

[5] Long Jin, Shuangjie Wang. Based on the analysis of the deformation area of permafrost subgrade height effect research [J]. Chinese and foreign road 2013, 6:33 (3).

[6]MingyiZhang, YuanmingLai,Zhiqiang Zhang,et al.Nonlinear analysis for the cooling effect of Qinghai-Tibet Railway embankment with different structures in permafrost regions [J].Cold Region Science and Technology,2005,42:237-249. 